\title{
DAS CONVERSAS NAS NOITES ESTRELADAS DA ALDEIA PARA A SALA DE AULA: A LITERATURA ORAL INDÍGENA COMO FONTE PARA A CONSTRUÇÃO DE MATERIAIS E MÉTODOS ADEQUADOS ÀS ESCOLAS INDÍGENAS
}

\author{
OF CONVERSATIONS VILLAGE STARTED NIGHTS TO THE CLASSROOM: \\ INDIGENOUS ORAL LITERATURE AS A SOURCE FOR CONSTRUCTION OF \\ MATERIALS AND METHODS SUITABLE FOR INDIGENOUS SCHOOLS
}

DOI: http://dx.doi.org/10.23926/RPD.2526-2149.2019.v4.n2.p546-558.id520

\author{
Thiago Silva e Silva \\ Mestre em Letras \\ (UNIFESSPA) \\ Técnico em Assuntos \\ Educacionais (IFMA) \\ Doutorando em Processos e \\ Manifestações Culturais \\ (Universidade FEEVALE) \\ thiago.silva@ifma.edu.br
}

Resumo: Este artigo analisa qualitativamente, considerando o arcabouço teórico de Munduruku (2014), Cascudo (2006), e dos Referenciais Curriculares Nacionais para as Escolas Indígenas, os resultados de uma oficina realizada, em 2018, com professores indígenas e não indígenas atuantes em aldeias Guajajara e Canela Ramkokamekrá, a qual propunha a produção de material diferenciado e a capacitação dos docentes para a adoção de metodologias que respeitassem os processos próprios de aprendizagem de cada comunidade. As análises indicam que a escola tem ajudado a cristalizar percepções infecundas sobre literatura e escrita, na medida em que desprestigia a oralidade. Por outro lado, observou-se também que as propostas metodológicas e os materiais construídos ao longo da oficina oferecem caminhos possíveis pelos quais a educação escolar indígena pode trilhar a fim de garantir um currículo intercultural, diversificado e diferenciado.

Palavras-chave: Educação Escolar Indígena. Interculturalidade. Literatura Oral Indígena.

\begin{abstract}
This paper aims to qualitatively analyze, considering the theoretical framework of Munduruku (2014), Cascudo (2006), and the National Curriculum References for Indigenous Schools, the results of a workshop held in 2018 with indigenous and nonindigenous teachers working in villages. Guajajara and Canela Ramkokamekrá, which proposed the production of differentiated material and the qualification of teachers for the adoption of methodologies that respected the learning processes of each community. Analyzes indicate that the school has helped to crystallize inaccurate perceptions about literature and writing as it discredits orality. On the other hand, it was also observed that the methodological proposals and materials built throughout the workshop offer possible ways in which indigenous school education can tread to ensure an intercultural, diverse and differentiated curriculum.
\end{abstract}

Keywords: Indigenous School Education. Interculturality. Indigenous Oral Literature. 


\section{Palavras iniciais}

Dados do Censo Escolar 2018 (MEC, 2019) apontam que havia no Brasil, naquele ano, 3.345 escolas indígenas, com 255.888 alunos matriculados e 22.590 professores. Apesar de numericamente expressiva, as escolas indígenas não têm recebido investimentos por parte do poder público na medida necessária a fim de que funcionem de forma ideal. É importante frisar que, além da melhoria da estrutura física dessas escolas, que hoje é bastante deficiente, o alcance de uma escola ideal que efetivamente considere os anseios das comunidades indígenas passa também, sem sombra de dúvida, pela formação de professores para atuarem na educação escolar indígena. Outro ponto sensível nesta temática, e que urge por atenção, toca a questão da produção de materiais (livros didáticos, paradidáticos, cartilhas, etc.) e métodos pedagógicos diferenciados.

Infere-se, contudo, que os problemas ora apontados são resultados de uma longa história em que os ameríndios foram subalternizados e silenciados, isto é, se arrasta desde a chegada dos portugueses à Ilha de Vera Cruz, atualmente, Brasil.

Munduruku (2012, p.29), ao tratar dos modelos de políticas indigenistas, apresenta o que pode ser considerado o primeiro período do processo histórico das relações entre população indígena e educação escolar indígena: o da catequese. Nesse período, os portugueses viam os indígenas como seres sem "alma", sem conhecimentos, selvagens e que por isso precisavam ser domesticados e catequisados. Assim, a função de ensiná-los foi incumbida aos jesuítas, perdurando até o início da República brasileira.

Já no início do século XX, muitas discussões foram travadas a respeito do futuro desses povos tradicionais e qual a responsabilidade do Estado sobre eles; o que resultou na criação, em 20 de julho de 1910, por meio do Decreto 8.072, da agência do Estado brasileiro denominada Serviço de Proteção aos Índios e Localização de Trabalhadores Nacionais ${ }^{1}$, incumbida de gerenciar, entre outras coisas, as novas políticas indigenistas.

Apesar de menos danosas que as políticas anteriores, essas novas diretrizes não foram capazes de reconhecer o protagonismo dos povos indígenas, pelo contrário, o SPI “[...] agia transferindo índios e liberando territórios indígenas para colonização e impunha uma pedagogia que alterava o sistema produtivo indígena" (PALADINO, 2010, p.112). Agora, sob a responsabilidade do Estado, a educação dada nas escolas que atendiam essas comunidades continuava desconsiderando os seus saberes tradicionais.

\footnotetext{
${ }^{1}$ Em 1918, passou a ser chamado de SPI (Serviço de Proteção ao Indígena) 
Mais tarde, em 1967, o SPI foi extinto e deu lugar à Fundação Nacional do Índio (FUNAI). Entretanto, a criação desse novo órgão não significou a mudança no paradigma integracionista, até então defendido pelo Estado brasileiro. Nesse sentido, Pacheco de Oliveira e Freire (2006, p. 131), ao citarem Magalhães (2003), ratificam que à FUNAI cabia a promoção de uma educação de base apropriada do índio visando sua progressiva integração na sociedade nacional.

Neste contexto árido, os povos indígenas intensificaram as mobilizações e reagiram contra as políticas indigenistas a que estavam submetidos. Assim, em 1980, nasce o primeiro movimento indígena de extensão nacional: a União das Nações Indígenas.

Com muita luta e a colaboração de outras organizações de apoio ao índio, a exemplo do Conselho Indigenista Missionário (CIMI), os povos originários brasileiros conseguiram o reconhecimento de inúmeros direitos na Constituição Federal de 1988, entre eles o de ter uma educação escolar indígena que utilize as suas línguas maternas e processos próprios de aprendizagem. A partir da promulgação da Carta Magna, vários documentos legais e orientativos foram sendo produzidos com o intuito de reforçar as bases em que deve estar assentada a educação escolar indígena.

À luz desse novo cenário, em que o arcabouço legal, orientativo e teórico apontam para uma educação escolar indígena que valorize os processos e conhecimentos tradicionais de cada povo, o presente artigo pretende analisar os resultados obtidos na execução de uma oficina realizada com professores indígenas e não indígenas atuantes em comunidades do povo Guajajara $^{2}$ e Canela Ramkokamekrá ${ }^{3}$, a qual propunha a produção de material diferenciado e a capacitação dos docentes para a adoção de metodologias que respeitem os processos próprios de aprendizagem de cada aldeia.

\section{O CAMINHO PERCORRIDO}

Este artigo é resultado de uma análise qualitativa sobre uma oficina ministrada a professores indígenas ${ }^{4}$ e não indígenas, em 2018, que atuavam em escolas das comunidades

\footnotetext{
${ }^{2}$ Habitam as Terras Indígenas do centro do Maranhão, nas regiões dos rios Pindaré, Grajaú e Mearim. Indígenas de várias aldeias próximas à cidade de Barra do Corda participaram da oficina. São do tronco linguístico Tupi. Outra denominação para esse povo é Tenetehara-Guajajara.

${ }^{3}$ Participaram apenas indígenas da aldeia Escalvado, localizada em Fernando Falcão - MA e a 70 KM a sudeste de Barra do Corda. São do tronco linguístico Jê.

${ }^{4}$ Em Escalvado, todos os professores participantes eram indígenas Canela. Já na outra oficina, ministrada no IFMA - Campus Barra do Corda, dos mais de 15 professores participantes, apenas 6 (seis) eram indígenas Guajajara.
} 
Escalvado, do povo Canela, e do povo Guajajara. A mesma oficina foi ministrada ${ }^{5}$ em momentos diferentes: primeiro na comunidade Escalvado, em Fernando Falcão - MA, e depois aos professores de escolas em território Guajajara.

Em síntese, as atividades da oficina se deram da seguinte forma: num primeiro momento, foi mostrado um panorama geral dos estudos sobre literatura oral e literatura escrita indígena; discutindo, simultaneamente, as ideias infundadas que insistem em dispor a oralidade e a escrita como opostas. Na sequência, aos docentes foi oportunizado falarem sobre como se dava a transmissão das tradições indígenas em cada comunidade e de que forma a escola tem aproveitado esses processos. Posteriormente, os participantes foram divididos em grupos. Em cada equipe, 1 (um) indígena contou aos demais integrantes de seu grupo 1 (uma) história que comumente se divulgava na sua comunidade. Desse momento de contação, cada membro da equipe fez o reconto escrito da narrativa. Por fim, 1 (um) integrante por grupo leu a todos o seu texto. A partir desse material produzido, que emergiu da memória oral, discutiu-se a construção de estratégias que pudessem auxiliar na utilização dessas narrativas, orais e/ou escritas, em sala de aula.

Registra-se, ainda, que a oficina foi originalmente intitulada Literatura Oral Indígena: práticas pedagógicas interculturais, em contexto escolar indígena, para a redução das desigualdades e era atividade integrante do projeto de extensão financiado pelo Fundo de Amparo à Pesquisa e ao Desenvolvimento Tecnológico do Estado do Maranhão (FAPEMA), através do Edital FAPEMA n 26/2018 - SNCT, solicitação SNCT - 04335/18 e executado pelo Instituto Federal de Educação, Ciência e Tecnologia do Maranhão - Campus Barra do Corda, sob a Coordenação da Prof ${ }^{a}$ Dra $^{a}$. Marinete Moura da Silva Lobo.

\section{Resultados}

O primeiro ponto a se discutir, e não é por acaso que virá primeiro, envolve as percepções que a escola, de forma geral, tem ajudado a cristalizar: o de que literatura é somente a arte da palavra escrita. Alicerçada ainda numa prática de letramento autônomo, em que concebe a escrita como um produto completo em si (ZAPPONE e YAMAKAWA, 2013, p. 186), essas percepções deixam a escrita e a oralidade em condição de rivais.

\footnotetext{
${ }^{5}$ Pretendia-se, inicialmente, reunir os dois povos indígenas em um só local e momento, a fim de possibilitar o diálogo simultâneo entre eles. Contudo, em face das dificuldades de logística, não foi possível.
} 
Ao iniciar essa abordagem, aos docentes participantes foi perguntado o que eles consideravam como literatura e como eles viam a relação entre a escrita e a oralidade. Ratificando o prólogo deste tópico, cerca de $75 \%$ consideraram literatura somente "aquelas histórias das cartilhas e dos livros que chegam à escola ${ }^{6}$ ". Na proporção idêntica à anterior, disseram que a escrita ou o seu domínio " garante a melhora das condições de vida".

Assim, pelas respostas, é possível fazer algumas inferências: (1) se literatura é somente o que se encontra nos livros, certamente não consideram literatura as narrativas orais contadas, normalmente pelos mais velhos, na maioria dessas comunidades indígenas; (2) se essas narrativas não estão nos livros, elas não servem para a sala de aula; (3) se a escrita funciona como um condão que garante a melhora das condições de vida, logo, os que não a dominam estão fadados ao fracasso.

Notadamente, essa supervalorização da escrita em detrimento da oralidade cria dois grupos na sociedade: os que sabem ler e escrever (os letrados) e os que não dominam a escrita (os chamados iletrados). Kleiman (1995, p. 25) alerta que esse tipo de agrupamento, que tem como pilar o domínio da escrita, pode criar concepções perigosas e fornecer argumentos para produzir o preconceito.

Sobre o termo literatura oral, Cascudo (2006, p.21) informa que ele foi utilizado pela primeira vez em 1881, por Paul Sébillot. Acrescenta, em seguida, que essa literatura, antes limitada aos provérbios, adivinhações, contos, etc. ampliou-se alcançando horizontes maiores. Segundo ele, a característica marcante dela é a persistência pela oralidade

Nesse sentido, foi discutido a literatura como um instrumento que vai além do texto escrito, abrangendo também as diversas manifestações culturais como a dança, o canto, o grafismo, as preces e as narrativas tradicionais. (MUNDURUKU, 2014, p. 176). Dessa forma, foi possível ampliar as concepções acerca de literatura, de escrita e de oralidade.

Por outro lado, é preciso dizer que, ao tratar desses assuntos, deve-se ter a cautela para não cair na ideia simplista de que não é importante aprender a ler e a escrever. Pelo contrário, essas são atividades necessárias na escola, mas que não suprimem o papel valioso da oralidade nem dão argumentos suficientes para supor que uma seja superior a outra. É imperioso reconhecer que são diferentes; que ambas apresentam estratégias também diferentes, mas, em momento algum rivalizam. Nesse sentido, Marcuschi (2007, p.15) diz que:

\footnotetext{
${ }^{6}$ Resposta dada pela maioria dos participantes.

${ }^{7}$ Resposta dada por um professor não indígena que sintetiza a maioria. 
Uma das posições defendidas nos ensaios aqui apresentados é a de que não há razão alguma para desprestigiar a oralidade e supervalorizar a escrita. Também não há razão alguma para continuar defendendo uma divisão dicotômica entre fala e escrita nem se justifica o privilégio da escrita sobre a oralidade. Ambas têm um papel importante a cumprir e não competem. Cada uma tem sua arena preferencial, nem sempre fácil de distinguir, pois são atividades discursivas complementares. Em suma, oralidade e escrita não estão em competição. Cada uma tem sua história e seu papel na sociedade.

$\mathrm{Na}$ sequência, ao oportunizar aos docentes, especialmente àqueles que se autoidentificavam como indígenas, um momento para compartilharem a maneira como as tradições de suas comunidades eram transmitidas de geração a geração e, ainda, de que forma a escola utilizava esses conhecimentos tradicionais; observou-se, pelas respostas, um quadro contrastante: na maioria das comunidades, a transmissão ocorria por meio das festas tradicionais e, principalmente, por meio da oralidade, em que os mais velhos, considerados guardiões da memória, repassam aos mais novos os ensinamentos de suas tradições, normalmente durante as noites estreladas; por outro lado, e aqui vem o contraste, em se tratando da escola, o currículo adotado não contemplava esses conhecimentos tradicionais; e pior, todo o material trazia apenas representações do contexto do Karaiw/Cupen ${ }^{8}$.

As declarações acima serviram para ratificar 3 (três) pontos: (1) a maioria das escolas dessas comunidades indígenas, que representam a ação do Estado, não atendia aos anseios das comunidades onde estavam instaladas, na medida em que não respeitavam os processos e conhecimentos tradicionais, conforme preconiza a Constituição Federal do Brasil de 1988, nos seus Artigos $210, \S 2^{\circ}$ e $215, \S 1^{\circ}$; (2) faltavam materiais adequados capazes de dar conta dessa demanda constitucional e (3) era preciso promover ações que visassem à capacitação dos profissionais para atuarem nesse segmento educacional.

A respeito dessas conclusões, a Lei de Diretrizes e Bases da Educação Nacional (LDBEN) nº 9.394/1996, no Artigo 79, § 2º, assevera que:

Art. 79. A União apoiará técnica e financeiramente os sistemas de ensino no provimento da educação intercultural às comunidades indígenas, desenvolvendo programas integrados de ensino e pesquisa

$[\ldots]$

$\S 2^{\circ}$ Os programas a que se refere este artigo, incluídos nos Planos Nacionais de Educação, terão os seguintes objetivos:

I - fortalecer as práticas socioculturais e a língua materna de cada comunidade indígena;

II - manter programas de formação de pessoal especializado, destinado à educação escolar nas comunidades indígenas;

\footnotetext{
${ }^{8}$ Os não indígenas são denominados pelos Guajajara e Canela como Karaiw e Cupen, respectivamente
} 
III - desenvolver currículos e programas específicos, neles incluindo os conteúdos culturais correspondentes às respectivas comunidades;

IV - elaborar e publicar sistematicamente material didático específico e diferenciado.

A despeito do que foi verificado, os professores da aldeia Escalvado relataram que já existiam várias ações em curso para garantir ao seu povo uma educação escolar intercultural, específica e diferenciada. Tais ações, segundo eles ${ }^{9}$, eram planejadas no âmbito da Licenciatura Intercultural e do Programa Saberes Indígenas na Escola. Sobre o referido programa, o FNDE (2019) informa que:

\begin{abstract}
Visa promover a formação continuada de professores da educação escolar indígena, especialmente daqueles que atuam nos anos iniciais da educação básica nas escolas indígenas; oferecer recursos didáticos e pedagógicos que atendam às especificidades da organização comunitária, do multilinguismo e da interculturalidade que fundamentam os projetos educativos nas comunidades indígenas; oferecer subsídios à elaboração de currículos, definição de metodologias e processos de avaliação que atendam às especificidades dos processos de letramento, numeramento $\mathrm{e}$ conhecimentos dos povos indígenas; fomentar pesquisas que resultem na elaboração de materiais didáticos e paradidáticos em diversas linguagens, bilíngues e monolíngues, conforme a situação sociolinguística e de acordo com as especificidades da educação escolar indígena.
\end{abstract}

Após essa breve consulta aos participantes da oficina, eles foram divididos em grupos, de forma que, no caso dos professores atuantes em Terras Indígenas dos Guajajara, em que o número de professores autodeclarados indígenas era pequeno, deveria em cada grupo ter, pelo menos, 1 (um) professor pertencente a essa etnia.

Figura 1 - Oficina com profs. Guajajara

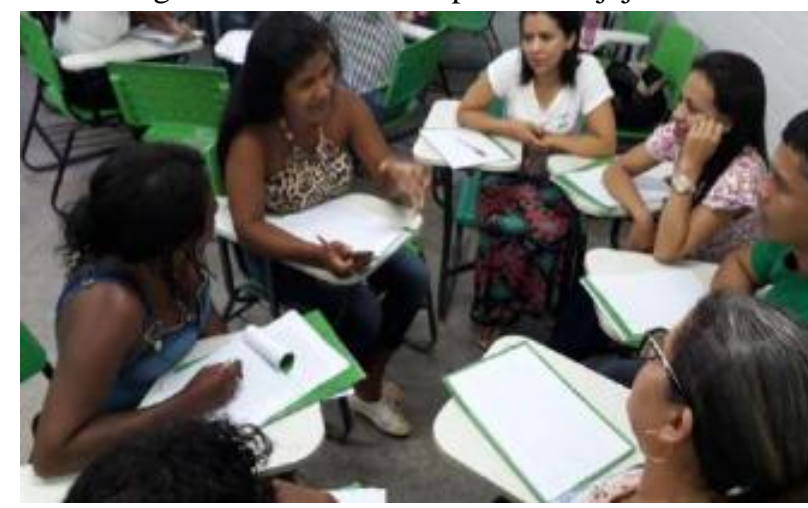

Arquivo do Pesquisador
Figura 2 - Oficina com profs. Canela

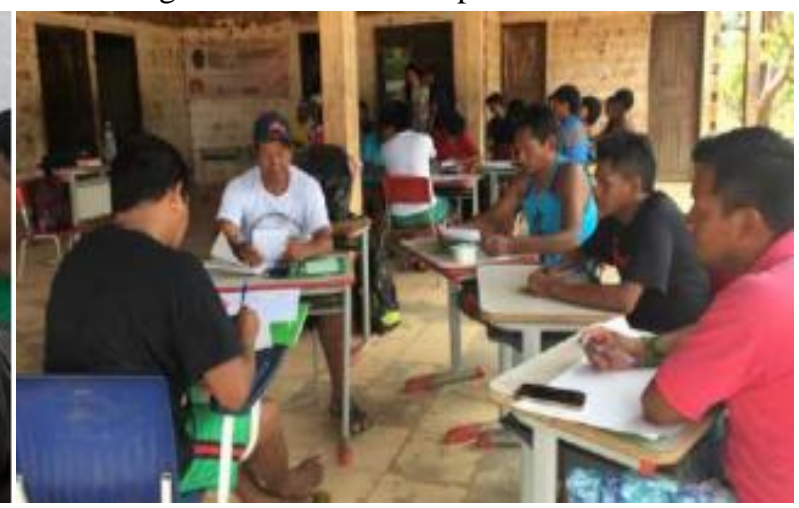

Arquivo do Pesquisador

Estando os grupos reunidos, 1 (um) professor indígena de cada equipe contou aos membros de seu grupo 1 (uma) história que comumente era ouvida na sua comunidade. Assim, esta etapa da atividade visava simultaneamente a produção de um material que partisse da memória oral, ou seja, que considerasse nessas produções os conhecimentos tradicionais, bem

\footnotetext{
${ }^{9}$ Professores que frequentavam curso de Licenciatura Intercultural e/ou o Programa Saberes Indígenas na Escola tinham percepções bem próximas do que pretendia a oficina alcançar
} 
como mostrar a eles que as atividades em sala de aula, em uma escola indígena, podem ser organizadas a partir das manifestações orais, podendo, inclusive, essa etapa ser repetida com os seus alunos. Ao refletirem sobre essa proposta, alguns dos participantes apontarem que, para os momentos de leitura e contação de histórias em sala de aula, eles poderiam estar convidando o ancião da aldeia.

Pelas reflexões dos professores, constata-se que as propostas alcançaram os objetivos previamente estabelecidos, além de apontarem para a necessidade de aproximação entre a escola e a comunidade, ou como disse um dos participantes: "Vamos trazer a aldeia para dentro da escola!" Vê-se, pois, que a maioria das escolas indígenas estão fisicamente dentro das comunidades, mas parecem constituir-se, devido ao seu currículo distante das realidades locais, em um outro mundo.

Sob outra perspectiva, é preciso perceber que as comunidades indígenas que militam por uma educação escolar que valorize a sua cultura são as mesmas que lutam pela existência de um diálogo entre os seus saberes tradicionais com os de outros povos. É, pois, nesse contexto que surge uma das demandas basilares dessa educação escolar: a interculturalidade.

Além da LDBEN, o Referencial Curricular Nacional para as Escolas Indígenas (RCNEI), de 1998, aponta para uma educação escolar indígena intercultural. Segundo este referencial, a interculturalidade se realiza quando há “ $O$ diálogo respeitoso entre a realidade dos próprios alunos e os conhecimentos vindos de diversas culturas humanas [...]” (RCNEI, 1998, p.60).

Pautando-se neste princípio, foi que a última etapa da oficina ocorreu: leitura dos textos produzidos a partir das histórias contadas, seguida da construção coletiva de estratégias que pudessem auxiliar na utilização dessas narrativas, orais e/ou escritas, em sala de aula. Para este recorte, serão analisados apenas dois $\operatorname{textos}^{10} \mathrm{e}$ as respectivas estratégias metodológicas sugeridas a partir deles: um do povo Canela, intitulado $A$ história do fogo ${ }^{11}$; e o outro dos Guajajara, denominado Menina moça.

A seguir é apresentada uma síntese do que contam cada narrativa examinada aqui.

\footnotetext{
${ }^{10}$ No total, foram produzidas a partir do imaginário indígena 6 (seis) narrativas, sendo 3 (três) de cada povo

${ }^{11}$ No âmbito da Licenciatura Intercultural ofertada pela Universidade Federal de Goiás (UFG), em 2017, um grupo de professores de Escalvado publicou um livro de literatura chamado de História do fogo - uma história do povo Canela
} 
Quadro 1 - Síntese das narrativas

\begin{tabular}{|c|c|}
\hline A história do fogo & Menina moça \\
\hline 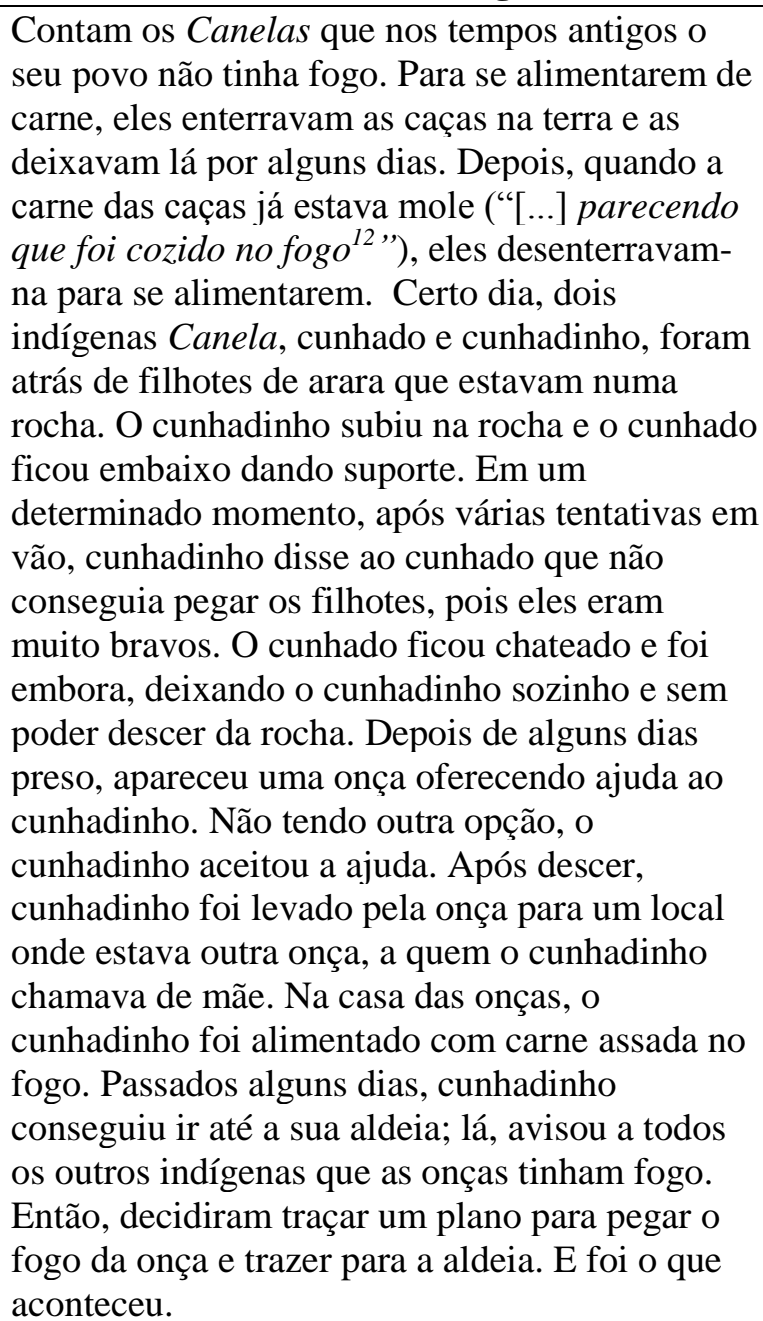 & $\begin{array}{l}\text { Em uma aldeia Guajajara, certa vez uma } \\
\text { indígena menstruou pela primeira vez. Seguindo } \\
\text { o ritual de passagem, a menina ficou reclusa por } \\
\text { sete dias em um quarto, onde passaram nela tinta } \\
\text { de jenipapo para que os espíritos ruins não se } \\
\text { aproximassem dela. Ao final do período de } \\
\text { reclusão, a menina não poderia tomar banho } \\
\text { sozinha no rio, contudo ela desobedeceu seus } \\
\text { pais: "Por }{ }^{13} \text { ter desobedecido, a mãe d'água a } \\
\text { levou nas correntezas do rio e nunca mais foi } \\
\text { vista" }\end{array}$ \\
\hline
\end{tabular}

Fonte: Arquivo do pesquisador

Das discussões sobre os textos acima, e procurando pautar-se na interculturalidade dos conhecimentos, várias estratégias que pudessem ser utilizadas em momentos de leitura foram construídas, entre elas, a de que, nesses momentos em sala de aula, o aluno deveria ser estimulado a fazer uma pesquisa sobre histórias de outros povos indígenas e não indígenas que tratassem das mesmas temáticas, destacando o que elas têm em comum e de diferente.

Simulando essa estratégia, os professores encontraram vários outros textos de autoria indígena que abordam a temática das histórias acima, a saber: sobre a origem do fogo, encontraram a lenda kaingang, lenda xavante e lenda kuikúru. Desses textos, observaram que povos pertencentes ao mesmo tronco linguístico narravam de forma muito parecida a mesma

\footnotetext{
${ }^{12}$ Fala de um dos contadores da história

${ }^{13}$ Trecho retirado de um texto produzido na oficina
} 
temática. Tal constatação já havia sido feita, em 2002, por Betty Mindlin, no texto $O$ fogo e a chama dos mitos:

\begin{abstract}
Nos índios, são animais variados, com freqüência, os donos originais do fogo. No mito Kaiapó-Gorotire da origem do fogo, um homem é abandonado pelo cunhado no alto de uma rocha porque foram juntos apanhar ninhos de arara, e quando o que subiu atira os ovos ao de baixo, estes se transformam em pedras. O que fica preso passa sede e fome, até ser salvo por uma onça pintada (macho). O onça o leva e lhe serve carne assada, que o homem não conhecia, pois a humanidade não tinha fogo. A mulher do onça, com o tempo, tenta devorar o rapaz, que um dia a mata e foge, levando a carne assada para sua aldeia. Os homens organizam uma expedição à casa das onças para roubar o fogo. Este mito existe de forma muito semelhante em outros povos Jê, como os Kaiapó, os Timbira orientais, os Xerente, os Apinaié, os Krahô. (MINDLIN, 2002, p. 153 grifos do autor).
\end{abstract}

Para a narrativa da Menina moça, os professores apontaram outra narrativa que pode ser resumida assim: seguindo a tradição dos Guajajara, a menina, ao menstruar pela primeira vez, tem que ficar reclusa dentro de casa. Nesse período, ela não pode comer todo tipo alimento nem tomar banho sozinha no rio, pois no rio tem uma cobra que se transforma em um homem bonito. Se ela for sozinha para o rio, esse homem bonito conquista a menina moça e depois suga o seu sangue, levando-a à morte.

A partir dessa outra versão da história da Menina moça, os participantes da oficina trouxeram à discussão a lenda do boto, a qual possui semelhanças (o fato de um animal se transformar em um lindo homem para seduzir as mulheres) e diferenças (na lenda do boto, a jovem seduzida engravida; na Menina moça, ela morre) se comparada com a narrativa indígena em análise.

Importa frisar que todas essas discussões criaram possibilidades metodológicas de estudo em sala de aula sobre a intertextualidade. Além desse conceito, foi vislumbrado o da efetivação de um ensino interdisciplinar, pensando-o como:

A interdisciplinaridade não dilui as disciplinas, ao contrário, mantém sua individualidade. Mas integra as disciplinas a partir da compreensão das múltiplas causas ou fatores que intervêm sobre a realidade e trabalha todas as linguagens necessárias para a constituição de conhecimentos, comunicação e negociação de significados e registro sistemático dos resultados. (BRASIL, 2000, p. 76).

Para concretização da interdisciplinaridade, foram propostas as seguintes atividades: (1) a partir da narrativa do fogo, o professor de Química poderia apresentar a concepção científica de como o fogo é produzido; (2) ou, da narrativa da Menina moça, abordar na disciplina de ciências assuntos atinentes ao corpo humano feminino, com ênfase à primeira menstruação, por exemplo.

Por fim, é bom que se diga que a apresentação de uma concepção da química a respeito do fogo, de forma exemplificativa, não deve servir para invalidar ou desmerecer os 
conhecimentos tradicionais da comunidade a respeito dessa temática, considerando que, na interdisciplinaridade, o objetivo não é anular a contribuição de cada ciência em particular, mas apenas uma atitude que venha a impedir que se estabeleça a supremacia de determinada ciência, em detrimento de outros aportes igualmente importantes. (FAZENDA, 2011, 59).

\section{CONSIDERAÇões FinaIS}

O recorte utilizado para análise neste artigo indica que a escola, de maneira geral, tem ajudado a cristalizar percepções infecundas sobre literatura e escrita, na medida em que desprestigia as práticas de oralidade. Em se tratando das escolas situadas em comunidades indígenas, essas percepções parecem acentuar mais ainda essa esterilidade, considerando que a maioria dessas comunidades ainda têm na oralidade a sua principal forma de transmissão de seus legados tradicionais, e a escola ainda a desconsidera. Apesar disso, observa-se, pelos depoimentos, que as Licenciaturas Interculturais e programas como o Saberes Indígenas na Escola têm contribuído para inibir tais percepções, bem como contribuem para a formação de docentes para atuarem em escolas indígenas.

Nos achados deste trabalho, foi possível observar, também, que as propostas metodológicas e os materiais construídos ao longo da oficina oferecem caminhos possíveis pelos quais a educação escolar indígena pode trilhar a fim de garantir um currículo intercultural, diversificado, diferenciado e que, acima de tudo, considera os conhecimentos tradicionais e processos próprios de aprendizagem das comunidades indígenas. Nesse sentido, tais propostas não pretendem se comportar como uma "receita de bolo".

Por último, mas longe de esgotar as discussões sobre a temática, conclui-se que, de fato, a mudança da atual situação da educação escolar indígena passa pela formação de professores, pela construção de materiais adequados às realidades de cada povo, pelo respeito aos conhecimentos tradicionais, assim como pela manutenção da interculturalidade, como anseiam as comunidades tradicionais.

\section{REFERÊNCIAS}

BRASIL. Constituição da República Federativa do Brasil de 1988. Disponível em: http://www.planalto.gov.br/ccivil_03/constituicao/constituicao.htm. Acesso em: 10/08/2019.

BRASIL. Decreto no 8.072, de 20 julho de 1910. Disponível em: http://planalto.gov.br/ccivil_03/decreto/1910-1929/D8072.htm. Acesso em: 10/08/2019.

BRASIL. Lei de Diretrizes e Bases da Educação Nacional de 1996. Disponível em: http://www.planalto.gov.br/ccivil_03/leis/19394.htm. Acesso em: 12/08/2019. 
BRASIL. Parâmetros Curriculares Nacionais - Ensino Médio. Ministério da Educação, 2000. Disponível em: http://portal.mec.gov.br/seb/arquivos/pdf/blegais.pdf Acesso em: 12/08/2019.

BRASIL. Referencial Curricular Nacional para as Escolas Indígenas. Ministério da Educação/Secretaria de Educação Fundamental. - Brasília: MEC/SEF, 1998.

CASCUDO, Luís da Câmara. Literatura Oral no Brasil. 2.ed. São Paulo: Global, 2006.

FAZENDA, Ivani Catarina Arantes. Integração e interdisciplinaridade no ensino brasileiro: efetividade ou ideologia. 6 ed. São Paulo: Edições Loyola, 2011.

FUNDO NACIONAL DE DESENVOLVIMENTO DA EDUCAÇÃO. Saberes indígenas na escola. Disponível em: http://www.fnde.gov.br/programas/bolsas-e-auxilios/eixos-deatuacao/lista-de-programas/item/6439-saberes-indigenas-na-escola Acesso em: 17/08/2019.

KLEIMAN, Ângela. Os significados do letramento: uma nova perspectiva sobre a prática social da escrita. Campinas, SP: Mercado das Letras, 1995

MARCUSCHI, Luiz Antônio. Fala e escrita. Orgs. Luiz Antônio Marcuschi e Angela Paiva Dionisio.1. ed., 1. reimp. — Belo Horizonte: Autêntica, 2007.

MINDLIN, Betty. O fogo e as chamas dos mitos. Estudos Avançados, São Paulo, vol. 16, n. 44, p. 149 - 169, 2002. Disponível em: http://www.revistas.usp.br/eav/issue/view/733 Acesso em $18 / 08 / 2019$.

MINISTÉRIO DA EDUCAÇÃO. MEC trabalha por avanços na educação escolar indígena. 2019. Disponível em: http://portal.mec.gov.br/busca-geral/206-

noticias/1084311476/75261-mec-trabalha-por-avancos-na-educacao-escolar-indigena. Acesso em: 15/08/2019.

MUNDURUKU, Daniel. O caráter educativo do movimento indígena brasileiro (1970 1990). São Paulo: Paulinas, 2012.

MUNDURUKU, Daniel. Literatura indígena e as novas tecnologias da memória. In: BELMIRO, Cecilia et. al. (Orgs.). Onde está a literatura? Seus espaços, seus leitores, seus textos, suas leituras. Belo Horizonte, MG: Editora UFMG, 2014. p.169 - 179.

PACHECO DE OLIVEIRA, João.; FREIRE, Carlos Augusto da Rocha. A presença indígena na formação do Brasil. Brasília: Ministério da Educação, Secretaria de Educação Continuada, Alfabetização e Diversidade; LACED/Museu Nacional, 2006. Disponível em: http://www.dominiopublico.gov.br/download/texto/me004372.pdf Acesso em 15/08/2019

PALADINO, Mariana. História e historiografia indígena. In: AMORIM, Claudia; PALADINO, Mariana. Cultura e Literatura Africana e Indígena. Curitiba: IESDE Brasil S.A., 2010, p. $101-121$.

ZAPPONE, Mirian Hisae Yaegashi e YAMAKAWA, Ibrahim Alisson. Letramento dominante x vernacular e suas implicações para o ensino da literatura. Muitas Vozes, Ponta Grossa, vol. 2, n.2, p. 185 - 198, 2013, DOI: 10.5212/MuitasVozes.v.2i2.0002. Disponível 
Revista Prática Docente (RPD)

ISSN: 2526-2149

em: www.revistas2.uepg.br/index.php/muitasvozes/article/download/6126/pdf_141 Acesso em: 10/06/2019.

Recebido em: 04 de setembro de 2019.

Aprovado em: 23 de dezembro de 2019. 